\title{
Osimertinib for Previously Treated Patients With Advanced EGFR T790M Mutation-Positive NSCLC: Tolerability and Diagnostic Methods From an Expanded Access Program
}

\author{
Edgardo S. Santos - Barry Kaplan - Eli Kirshner • Elisabeth F. Croft • \\ Lecia V. Sequist · MyDoanh Chau · Jiefen Munley · Geoffrey R. Oxnard
}

Received: April 3, 2018 / Published online: May 25, 2018

(C) The Author(s) 2018

\section{ABSTRACT}

Introduction: The osimertinib (AZD9291) US Expanded Access Program (EAP) provided compassionate access to osimertinib prior to US Food and Drug Administration (FDA) approval for patients with advanced/metastatic epidermal growth factor receptor (EGFR) T790M-positive non-small cell lung cancer (NSCLC) following progression on tyrosine kinase inhibitors (TKIs) targeting EGFR. Here, we report the patient demographics, safety and tolerability,

MyDoanh Chau is also known as Maiyan Chau.

Enhanced digital content To view enhanced digital content for this article go to https://doi.org/10.6084/ m9.figshare.6247304.

E. S. Santos $(\bowtie)$

Lynn Cancer Institute, Boca Raton, FL, USA

e-mail: esantos@brrh.com

\section{B. Kaplan}

Queens Medical Associates, PC-New York-

Presbyterian Queens Hospital, Fresh Meadows, New

York, NY, USA

E. Kirshner

Valley Health System, Westwood, Los Angeles, CA, USA

E. F. Croft

AstraZeneca, Cambridge, UK and diagnostic methods used for T790M testing in the EAP.

Methods: Adult patients with EGFR T790Mpositive NSCLC following progression on prior EGFR-TKI therapy (irrespective of line of therapy) were enrolled in the EAP and treated with $80 \mathrm{mg}$ osimertinib once daily until dose reduction, discontinuation, or completion of the EAP following FDA approval (November 2015). Various testing methods were allowed for the required T790M testing.

Results: In total, 248 patients from 25 centers throughout the USA were enrolled in the EAP. The starting dose of $80 \mathrm{mg}$ osimertinib once daily was maintained for $96 \%(n=238)$ of patients over the duration of the EAP (median duration of exposure 84 days). Most patients (overall $83 \% \quad[n=205 / 238]$; patients aged $\geq 75$ years $83 \%[n=48 / 58]$ ) completed the EAP

\section{V. Sequist}

Massachusetts General Hospital, Harvard Medical School, Boston, MA, USA

\section{Chau}

AstraZeneca, Gaithersburg, MD, USA

J. Munley

AstraZeneca, Wilmington, DE, USA

G. R. Oxnard

Dana-Farber Cancer Institute, Harvard Medical

School, Boston, MA, USA 
and transitioned to commercially available osimertinib following FDA approval. Serious adverse events considered to be treatment related by investigators were reported in five patients $(2 \%)$, all aged $\geq 65$ years, and were dyspnea, deep vein thrombosis, femur fracture, alanine aminotransferase increase, and pneumonitis, respectively. A variety of biospecimen types were collected: solid tumor tissue (73\%), blood $(20 \%)$, cytology $(6 \%)$, and urine $(2 \%)$. PCR-based methods were most commonly used for determining EGFR mutation status (47\%) followed by next-generation sequencing (33\%). Conclusion: In a real-world setting, osimertinib was well tolerated, and most patients, including patients aged $\geq 75$ years, transitioned to commercially available osimertinib following FDA approval. The EAP suggests there has been an uptake of minimally invasive T790M testing methods at some centers.

Funding: AstraZeneca (Wilmington, DE, USA).

Keywords: Compassionate use; EGFR; EGFRTKI; Non-small cell lung cancer; Osimertinib

\section{INTRODUCTION}

The epidermal growth factor receptor (EGFR) pathway is one of the most common oncogenic pathways found either mutated or overexpressed in non-small cell lung cancer (NSCLC) [1-3]. In those patients with EGFR gene (EGFR)sensitizing mutations, the recommended firstline therapy consists of a first- or second-generation tyrosine kinase inhibitor (TKI) that targets EGFR, such as erlotinib, gefitinib, or afatinib [4]. Although EGFR-TKI treatment provides clinical benefit in patients with EGFR mutation-positive NSCLC, most patients develop resistance after a median progressionfree survival (PFS) of approximately 9-13 months [5-10]. Secondary mutations commonly drive EGFR-TKI-acquired resistance, such as EGFR T790M, which is reported in approximately $50-60 \%$ of patients with NSCLC following prior TKI therapy [11-15].

Osimertinib is an oral, central nervous system (CNS)-active, third-generation EGFR-TKI that is selective for both EGFR-sensitizing and
EGFR T790M resistance mutations [16-18]. Osimertinib was approved in November 2015 by the US Food and Drug Administration (FDA) for patients with metastatic EGFR T790M-positive NSCLC, as detected by an FDA-approved test, following progression on EGFR-TKI therapy. The phase 2 and 3 clinical studies (AURA trials) demonstrated that, following progression on EGFR TKI therapy, patients with T790M-positive NSCLC treated with osimertinib had median PFS ranging from 10 to 12 months [18-20]. The objective response rate (ORR) in the phase 3 trial (AURA 3) was 71\% (95\% confidence interval [CI] 65-76) in patients treated with osimertinib compared with those on chemotherapy (ORR 31\%; 95\% CI 24-40) [19]. Osimertinib was well tolerated in these trials with low rates of adverse events (AEs) and drug-related AEs, and few study discontinuations. The most common AEs in osimertinib-treated patients were diarrhea $(41 \%)$, rash $(34 \%)$, dry skin $(23 \%)$, and paronychia (22\%) [19]. The phase 3 FLAURA trial demonstrated the superior efficacy of osimertinib compared with standard EGFRTKIs (erlotinib or gefitinib) as first-line treatment for patients with advanced NSCLC and with at least one of the two most common EGFR-TKI-sensitizing mutations (i.e., L858R mutation or exon 19 deletion) (PFS 18.9 vs. 10.2 months, respectively; hazard ratio for disease progression or death $0.46 ; 95 \%$ CI $0.37-0.57 ; p<0.001)$ [21]. The safety profiles were similar in the two treatment arms in the FLAURA trial, with lower rates of severe $(\geq$ grade 3) AEs with osimertinib than with the standard EGFR-TKIs (34 vs. 45\%) [21]. The US osimertinib (AZD9291) Expanded Access Program (EAP) was developed to provide compassionate access to osimertinib in the USA after enrollment in clinical trials had closed but prior to FDA approval for patients with advanced or metastatic EGFR T790M-positive NSCLC following progression on prior EGFRTKI therapy. Here, we report the real-world patient demographics, the safety and tolerability, and the diagnostic methods used for T790M testing in the EAP in patients treated with osimertinib. 


\section{METHODS}

\section{Expanded Access Program}

The US AZD9291 EAP was open for enrollment from May 29, 2015, to November 20, 2015, prior to FDA approval of osimertinib. Following FDA approval and at investigator discretion, patients benefiting from osimertinib could be transitioned to the commercially available product within approximately 60 days. Patient visits and medical care in the EAP were performed at the discretion of the treating physician and per standard of care.

Adult patients (aged $\geq 18$ years) with locally advanced or metastatic EGFR T790M-positive NSCLC not amenable to curative surgery or radiotherapy and with a World Health Organization performance status of $0-2$ who received $\geq 1$ line of prior therapy including $\geq 1$ EGFR-TKIs were eligible. T790M-positive status determined from any biospecimen type and any testing platform was considered to be sufficient for EAP entry. Patients with symptomatic CNS metastases who were neurologically unstable or had a past medical history of interstitial lung disease (ILD), previous treatment with osimertinib, treatment with EGFR-TKIs within 7 days before program initiation, cytotoxic chemotherapy within 14 days of program initiation, or any unresolved grade $\geq 3$ toxicity from prior therapy (based on Common Terminology Criteria for Adverse Events) were excluded. There were no restrictions on concomitant drugs other than potent cytochrome P450 3A4 inhibitors and inducers. Investigators were advised that medical products known to have interactions with osimertinib, such as those that may increase or decrease osimertinib exposure, should be avoided.

Osimertinib was administered at a dose of $80 \mathrm{mg}$ once daily but could be reduced to $40 \mathrm{mg}$ once daily if patients experienced a grade $\geq 3$ and/or unacceptable toxicity (any grade) considered to be related to the osimertinib therapy by the investigator. The once-daily $80 \mathrm{mg}$ dose of osimertinib was chosen based on the available safety, tolerability, pharmacokinetics, and efficacy data from a phase 1 clinical trial in a similar patient population [15]. Patients (except for those with insulin-dependent diabetes) fasted for $\geq 1 \mathrm{~h}$ prior to dosing and $\geq 2 \mathrm{~h}$ post dose. Doses were administered approximately $24 \mathrm{~h}$ apart at the same time each day. Missed doses were permitted within a 12 -h window; otherwise, the next scheduled dose was administered.

\section{Compliance with Ethics Guidelines}

This EAP was approved by the FDA and institutional review boards, was performed in accordance with the ethical principles outlined in the Declaration of Helsinki, and was consistent with the International Conference on Harmonisation/Good Clinical Practice Guidelines. Patients provided informed consent prior to enrollment.

\section{Diagnostic Testing}

For required T790M diagnostics, various testing methods and biospecimen types were permitted for analysis, and all tumor biopsy platforms were accepted. At baseline, information regarding biospecimen samples used for mutational testing was collected, including laboratory name and location, biospecimen type collected (tissue, plasma, urine, cytology), site of tissuebiopsy sample, testing methodology and platforms, and the test result. Descriptions of specific testing methods and platforms were limited to the information provided by each investigator. Samples were submitted to a local Clinical Laboratory Improvement Amendments-certified laboratory for T790M testing using an appropriately validated test when available. Alternatively, the sample was sent to a designated local or central laboratory for analysis.

\section{Data Collection}

This program was not designed to assess the real-world effectiveness of osimertinib, and disease response was collected at investigator discretion but not mandated by the EAP protocol. Data collection prior to program initiation 
was limited to information required to determine patient eligibility, demographics, and prior cancer treatments. During the program, data on osimertinib exposure, start and stop dates, and reason for discontinuation were collected. Patients were followed for safety evaluation until 30 days following the last dose of osimertinib. Investigators were required to collect and report serious AEs (SAEs) from the time of informed consent through the time of the follow-up contact at 30 days after the last dose. Data on non-serious AEs were not consistently collected by investigators in the EAP.

\section{Statistical Analysis}

All analyses were based on the full analysis set, which consisted of patients who received $\geq 1$ dose of osimertinib. Statistical analyses were performed using SAS ${ }^{\circledR}$ version 9.3 software (SAS Institute, Cary, NC, USA). Descriptive statistics were used for continuous and categorical variables. Because the incidence of missing measurements was expected to be low, these were not imputed.

\section{RESULTS}

\section{Patient Characteristics}

A total of 248 patients from 25 centers across the USA were enrolled and treated with osimertinib as part of the EAP. Enrollment in the EAP increased from May through October and decreased around the time of FDA approval of osimertinib, which was November 13, 2015 (Fig. 1). The median age of patients was 65 (range 31-91) years, including 127 patients (51\%) aged $\geq 65$ years (Table 1 ), among whom $58(23 \% ; 58 / 248)$ were aged $\geq 75$ years. The majority of patients were female (69\%) and white $(71 \%)$. As per the inclusion criteria for the EAP, all patients had received $\geq 1$ prior TKI treatment, and most patients (85\%) had received $\geq 2$ prior cancer treatments. Erlotinib was the most commonly reported prior EGFRTKI therapy (95\%; $n=236 ;$ Fig. 2). Seventy patients $(28 \%)$ had received prior treatment with afatinib, and 36 patients (15\%) had received rociletinib. Patients in the EAP were heavily pretreated. The distribution of the most common chemotherapy regimens used (administered to $>20$ patients) prior to osimertinib EAP was: carboplatin and pemetrexed $(n=68 ; 27 \%) ; \quad$ cisplatin and pemetrexed $(n=25 ; 10 \%)$; pemetrexed $(n=25 ; 10 \%)$; nivolumab $(n=23 ; 9 \%)$; carboplatin and paclitaxel $(n=22 ; 9 \%)$; and carboplatin, paclitaxel, and bevacizumab $(n=21 ; 8 \%)$.

\section{Patient Disposition and Duration of Exposure}

Once osimertinib was approved in the USA on November 13, 2015, most patients (83\%; $n=205)$ transitioned to commercial osimertinib treatment and thus were considered as having completed the EAP (Table 2). Median program duration was 84 (range 3-252) days for the overall population and 90 (range 18-212) days in patients who transitioned to the commercial supply. A total of 115 patients remained on treatment for $>90$ days, of whom approximately $90 \%(n=103)$ transitioned to commercially available osimertinib. Of the 36 patients with prior treatment with rociletinib, 29 (81\%) transitioned to the commercial supply of osimertinib. Among the 43 patients who discontinued the EAP treatment, the most common reasons were disease progression $(n=17)$ and death $(n=12$; Table 2$)$. In the population aged $\geq 75$ years, 48 of 58 patients $(83 \%)$ converted to the commercial supply; the remaining ten patients discontinued the EAP because of disease progression $(n=5)$, death $(n=3)$, or patient decision $(n=2)$.

The starting dose of $80 \mathrm{mg}$ osimertinib administered once daily was maintained over the entire program duration for $96 \%(n=238)$ of patients. Ten patients (4\%) had their dose of osimertinib reduced from 80 to $40 \mathrm{mg}$ once daily because of treatment intolerance $(n=3)$, AEs $(n=1)$, or other reasons $(n=6$; Table 2$)$. Most dose reductions $(n=9)$ were reported in patients aged $\geq 65$ years. One dose reduction was reported for a patient in the population aged $<65$ years, and six were reported in the 


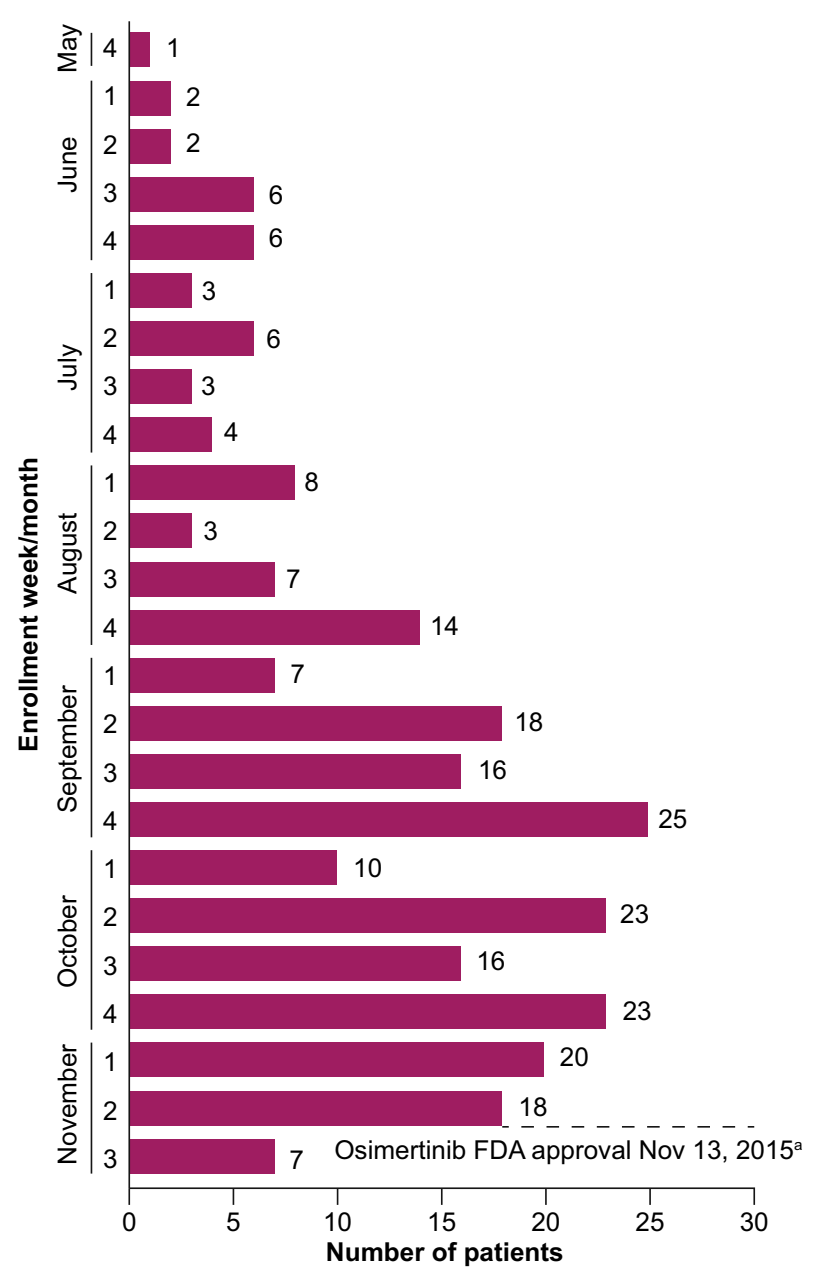

Fig. 1 Enrollment chart of the Expanded Access Program. Date of informed consent indicates when a patient was enrolled. ${ }^{a}$ Osimertinib was approved in the USA by the US Food and Drug Administration (FDA) on November 13, 2015 for the treatment of patients with metastatic

population aged $\geq 75$ years. Dose interruption occurred in 12 patients (5\%), with the most common reason being SAEs $(n=1)$, intolerance $(n=1)$, or other $(n=10)$; the majority of these SAEs $(n=9)$ were observed in patients aged $\geq 75$ years.

\section{Safety}

During the EAP, SAEs were reported in 19\% (48/ 248 ) of all patients (Table 3$)$ and in $28 \%(16 / 58)$ of patients aged $\geq 75$ years. The majority of SAEs were considered by the investigators to be epidermal growth factor receptor gene (EGFR) T790Mpositive non-small cell lung cancer, as detected by a US FDA-approved test, whose disease had progressed on or after therapy with a tyrosine kinase inhibitor targeting EGFR

unrelated to osimertinib, with the exception of five patients (2\%) who developed dyspnea, deep vein thrombosis (DVT), femur fracture, alanine aminotransferase (ALT) increase, and pneumonitis. Investigators considered the SAEs in these five patients to be related to osimertinib. All five patients were aged $\geq 65$ years, including four patients aged $\geq 75$ years.

A total of 19 deaths (8\%) were reported during the EAP, most of which were attributed to disease progression and/or respiratory complications $(n=16 ; 84 \%)$. The reported case of pneumonitis in a 75 -year-old female patient was 
Table 1 Patient demographics

\begin{tabular}{lllll}
\hline $\begin{array}{l}\text { Patient } \\
\text { demographics }\end{array}$ & $\begin{array}{l}\text { All patients } \\
(\boldsymbol{N}=\mathbf{2 4 8})\end{array}$ & $\begin{array}{l}\text { Patients aged } \\
<\mathbf{6 5} \text { years }(\boldsymbol{n}=\mathbf{1 2 1})\end{array}$ & $\begin{array}{l}\text { All patients aged } \\
\mathbf{2 6 5} \text { years }(\boldsymbol{n}=\mathbf{1 2 7})\end{array}$ & $\begin{array}{l}\text { All patients aged } \\
\mathbf{2 7 5} \text { years }(\boldsymbol{n}=\mathbf{5 8})\end{array}$ \\
\hline $\begin{array}{l}\text { Median age, years } \\
\text { (range) }\end{array}$ & $65(31-91)$ & $56(31-64)$ & $74(65-91)$ & $79(75-91)$ \\
$\begin{array}{l}\text { Sex, } n(\%) \\
\text { Female }\end{array}$ & $171(69)$ & $81(67)$ & $90(71)$ & $42(72)$ \\
Male & $77(31)$ & $40(33)$ & $37(29)$ & $16(28)$ \\
Race, $n(\%)$ & $175(71)$ & $84(69)$ & $91(72)$ & $48(83)$ \\
White & $12(5)$ & $6(5)$ & $6(5)$ & $1(2)$ \\
African & & & $8(14)$ \\
American & $51(21)$ & $25(21)$ & $26(20)$ & $1(2)$ \\
Asian & $10(4)$ & $6(5)$ & $4(3)$ & \\
Other & & &
\end{tabular}

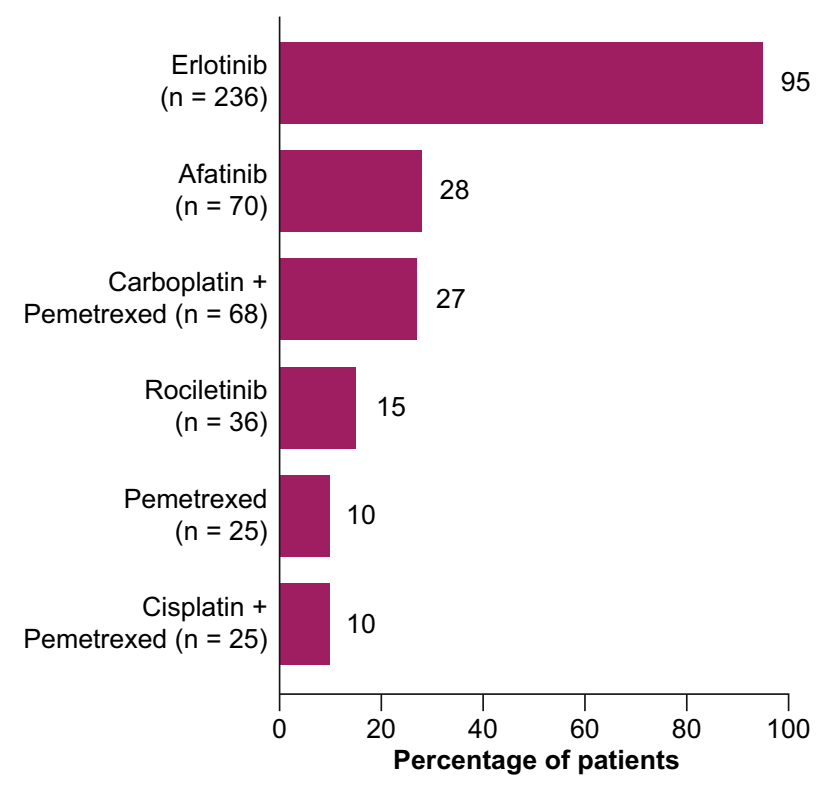

Fig. 2 Overall prior cancer treatments (includes prior cancer treatments received by $\geq 10 \%$ of overall population). A patient can have more than one prior cancer treatment

fatal and deemed by the investigator to be related to treatment; however, because the patient died outside of the clinical trial, and the case was retrospectively reported, the diagnosis could not be confirmed owing to the limited clinical information available. Other causes of death unrelated to osimertinib included cerebrovascular diseases and CNS infection $(n=1)$, hypotension and kidney failure $(n=1)$, and acute cerebrovascular accident and disseminated intravascular coagulation $(n=1)$. 
Table 2 Patient disposition: drug exposure and dose modifications

\begin{tabular}{|c|c|c|c|c|}
\hline & $\begin{array}{l}\text { All patients } \\
(N=248)\end{array}$ & $\begin{array}{l}\text { Patients aged } \\
<65 \text { years } \\
(n=121)\end{array}$ & $\begin{array}{l}\text { All patients aged } \\
\geq 65 \text { years }(n=127)\end{array}$ & $\begin{array}{l}\text { All patients aged } \\
\geq 75 \text { years }(n=58)\end{array}$ \\
\hline $\begin{array}{l}\text { Patients who converted to commercial } \\
\text { supply }, n(\%)\end{array}$ & $205(83)$ & $99(82)$ & $106(84)$ & $48(83)$ \\
\hline $\begin{array}{l}\text { Reasons for withdrawal prior to EAP } \\
\text { completion, } n(\%)\end{array}$ & $43(17)$ & $22(18)$ & $21(17)$ & $10(17)$ \\
\hline Disease progression & $17(7)$ & $8(7)$ & $9(7)$ & $5(9)$ \\
\hline Death & $12^{\mathrm{b}}(5)$ & $5(4)$ & $7(6)$ & $3(5)$ \\
\hline Other & $6^{c}(2)$ & $5(4)$ & $1(1)$ & 0 \\
\hline Patient decision & $3(1)$ & 0 & $3(2)$ & $2(3)$ \\
\hline Adverse event & $2^{\mathrm{d}}(1)$ & $1(1)$ & $1(1)$ & 0 \\
\hline Lost to follow-up & $2^{\mathrm{e}}(1)$ & $2(2)$ & 0 & 0 \\
\hline Investigator decision & $1(0.4)$ & $1(1)$ & 0 & 0 \\
\hline $\begin{array}{l}\text { Median duration of exposure, days } \\
\text { (range) }\end{array}$ & $84(3-252)$ & NR & NR & NR \\
\hline $\begin{array}{l}\text { Median duration of exposure in EAP- } \\
\text { completed patients, days (range) }\end{array}$ & $90(18-212)$ & NR & NR & NR \\
\hline \multicolumn{5}{|l|}{ Dose modifications, $n(\%)$} \\
\hline Dose reduction & $10(4)$ & $1(1)$ & $9(7)$ & $6(10)$ \\
\hline Treatment intolerance & $3(1)$ & 0 & $3(2)$ & $2(3)$ \\
\hline SAE & $1^{\mathrm{f}}(0.4)$ & 0 & $1(1)$ & $1(2)$ \\
\hline Other & $6^{g}(2)$ & $1(1)$ & $5(4)$ & $3(5)$ \\
\hline Dose interrupted & $12(5)$ & $3(3)$ & $9(7)$ & $9(16)$ \\
\hline Treatment intolerance & $1(0.4)$ & 0 & $1(1)$ & $1(2)$ \\
\hline SAE & $1^{\mathrm{h}}(0.4)$ & $1(1)$ & 0 & 0 \\
\hline Other & $10^{\mathrm{i}}(4)$ & $2(2)$ & $8(6)$ & $8(14)$ \\
\hline
\end{tabular}

EAP Expanded access program, $N R$ not reported; $S A E$ serious adverse event

a Approval by the US Food and Drug Administration (FDA) was received November 13, 2015

b There were 19 deaths reported in the EAP; 7 had study disposition categories other than death reported before the date of death

c Other includes 2 comorbidities, 3 international patients, and 1 patient decision

d Adverse events were mental status change (unrelated) and dyspnea (drug-related)

${ }^{\mathrm{e}}$ Unsuccessful contact with patient despite every effort made by clinician

${ }^{\mathrm{f}}$ Fatigue and dyspnea (unrelated to drug)

g Other reasons for dose reduction included adverse events such as rash, diarrhea, vomiting, fatigue, tachycardia, physician discretion, and dry mouth

h Constipation and seizure (unrelated to drug)

i Other reasons for dose interruption included feeling unwell, brain radiation, urinary tract infection, thrombocytopenia, respiratory issues, fatigue, hospitalization, suspected pneumonitis that was subsequently ruled out by $\mathrm{X}$-ray, and insurance coverage 
Table 3 Patient safety

\begin{tabular}{|c|c|c|c|c|}
\hline Patient safety & $\begin{array}{l}\text { All patients } \\
(N=248)\end{array}$ & $\begin{array}{l}\text { Patients aged } \\
<65 \text { years }(n=121)\end{array}$ & $\begin{array}{l}\text { All patients aged } \\
\geq 65 \text { years }(n=127)\end{array}$ & $\begin{array}{l}\text { Patients aged } \\
\geq 75 \text { years }(n=58)\end{array}$ \\
\hline $\begin{array}{l}\text { Patients with SAEs, } \\
n(\%)\end{array}$ & $48(19)$ & $20(17)$ & $28(22)$ & $16(28)$ \\
\hline $\begin{array}{l}\text { Number of reported } \\
\text { SAEs, } n\end{array}$ & 92 & 37 & 55 & 33 \\
\hline $\begin{array}{l}\text { Patients with drug- } \\
\text { related SAEs, } n(\%)\end{array}$ & $5(2)$ & 0 & $5(4)$ & $4(7)$ \\
\hline $\begin{array}{l}\text { Number of drug-related } \\
\text { SAEs, } n\end{array}$ & 5 & 0 & 5 & 4 \\
\hline Drug-related SAEs & $\begin{array}{l}\text { See age group } \\
\text { results }\end{array}$ & None & \multicolumn{2}{|c|}{$\begin{array}{l}\text { ALT increase, DVT, dyspnea, femur fracture, } \\
\text { pneumonitis }\end{array}$} \\
\hline
\end{tabular}

$A L T$ Alanine aminotransferase; $D V T$ deep vein thrombosis; $S A E$ serious adverse event

\section{Diagnostic Testing and Program Centers}

All 248 patients had EGFR T790M-positive NSCLC, which was determined at screening. In this real-world setting, various biospecimen types (tissue, blood, cytology, and urine) and diagnostic testing methods were used to confirm T790M mutation status (Table 4). Overall, the majority of biospecimens tested (73\%; $n=180$ ) were solid tumor tissue samples; blood specimens were collected from 49 patients (20\%).

Variation in biospecimen type was reported among and within EAP centers, which were located across the USA (Fig. 3). The majority of EAP centers $(n=19)$ used more than one biospecimen type for testing, and the remaining six centers used only one biospecimen type. Of the 25 centers conducting diagnostic testing, 23 used tissue, 19 used blood, six used cytology, and three used urine. Overall, a total of $80 \%$ $(n=20)$ of EAP centers obtained specimens for testing using minimally invasive methods from blood or urine.

PCR-based methods as well as sequencing methods, such as bidirectional and next-generation sequencing (NGS), were the most common methodologies for determining T790M mutation status and varied within the EAP (Table 4). PCR-based methods were the most commonly used among the different EAP centers $(47 \% ; n=117)$. NGS was utilized in $33 \%$ $(n=82)$ of testing cases and was the only method used across all biospecimen collection types. Specific platforms commonly reported ( $\geq 10$ samples) included Guardant360 $(n=30$; Guardant Health, Redwood City, CA, USA), FoundationOne ${ }^{\circledR} \quad(n=18$; Foundation Medicine, Cambridge, MA, USA), SNaPshot ${ }^{\circledR}(n=17$; Life Technologies, Carlsbad, CA, USA), the cobas ${ }^{\circledR}$ EGFR Mutation Test $(n=11$; Roche Molecular Diagnostics, Pleasanton, CA, USA), and GeneStrat ${ }^{\circledR}\left(n=10\right.$; Biodesix ${ }^{\circledR}$, Boulder, CO, USA).

\section{DISCUSSION}

In this article, we report data obtained from 248 patients who received expanded access to osimertinib, an oral, CNS-active, third-generation TKI that is selective for both EGFR-sensitizing and EGFR T790M resistance mutations. The US osimertinib EAP provided compassionate access to the agent for patients with EGFR T790M-positive NSCLC following the development of resistance to first- and second-generation EGFR-TKIs. As the EAP was not intended to evaluate the real-world effectiveness of osimertinib for treating these patients, the focus of our report is on the demographics and disposition 


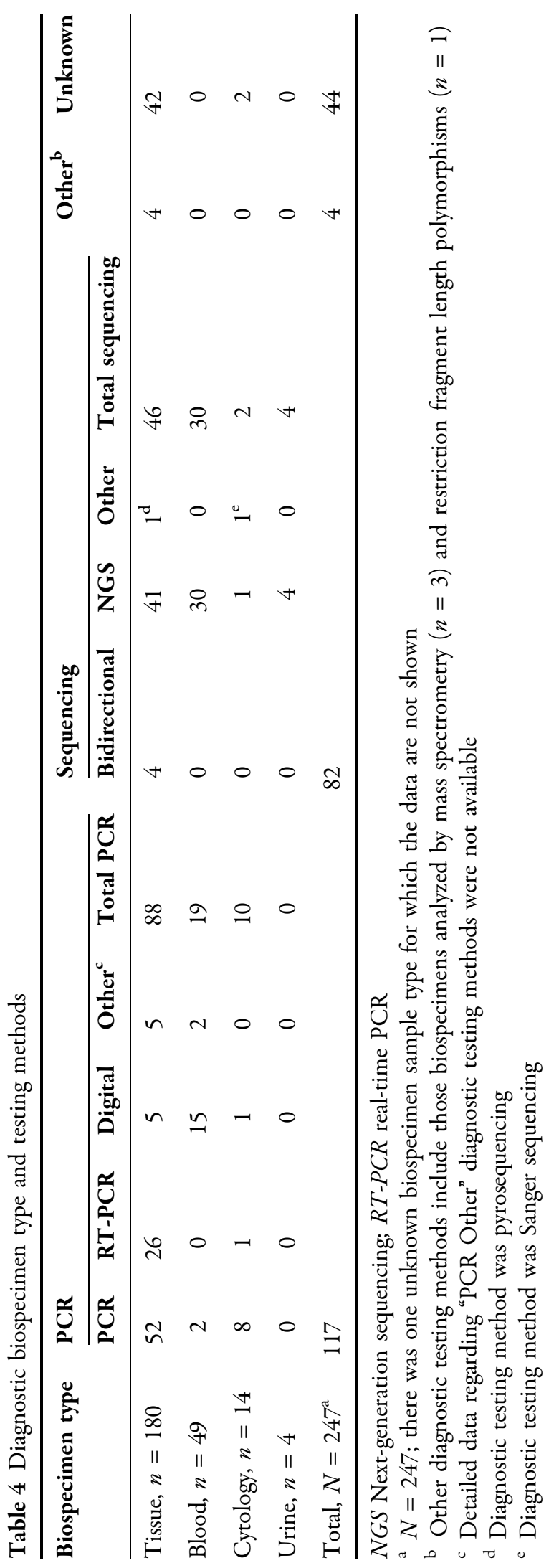

of patients, the safety and tolerability of the agent, and the methods of evaluation of T790M mutation status. The data obtained suggest that osimertinib was generally well tolerated and that there is uptake of minimally invasive T790M testing methods at some centers that use blood and urine as biospecimens.

The EAP was terminated when osimertinib was made commercially available following its FDA approval in November 2015 for the treatment of this patient population. Because the majority of patients were continuing to receive benefit from osimertinib therapy at the end of the EAP, most patients (83\%) transitioned to commercial use. The rate of completers was the same regardless of age, including patients aged $\geq 75$ years $(83 \%)$. This suggests that osimertinib was well tolerated, even in those who potentially had significant comorbidities or who were in generally poorer health, and is consistent with previous studies that have shown that EGFR-TKIs are well tolerated with a mild toxicity profile in elderly patient populations [22, 23]. Historically, clinicians have been reluctant to aggressively treat older patients owing to a fear of a greater risk of toxicities [24], but $50 \%$ of patients with NSCLC are aged $>70$ years at diagnosis [23]. Thus, identifying agents, such as osimertinib, that are well tolerated in this population is clinically relevant.

A requirement for entry into the EAP was that all patients had to have received $\geq 1$ prior TKI treatment regardless of the number of treatments received; most patients $(85 \%)$ had received $\geq 2$ prior cancer treatments. Prior TKI therapies included erlotinib (95\%), afatinib (28\%), and rociletinib (15\%). It should be noted that gefitinib was not approved in the USA until after the initiation of the EAP. Thus, this was a heavily pretreated population, and although efficacy was not assessed as part of the EAP, the high proportion of patients who transitioned to a commercial supply of osimertinib indicates that these patients continued to derive clinical benefit from T790M inhibition following progression. These results support the clinical trials program (AURA trials) for osimertinib that demonstrated clinical benefit in patients who had previously received prior EGFR-TKI therapy 


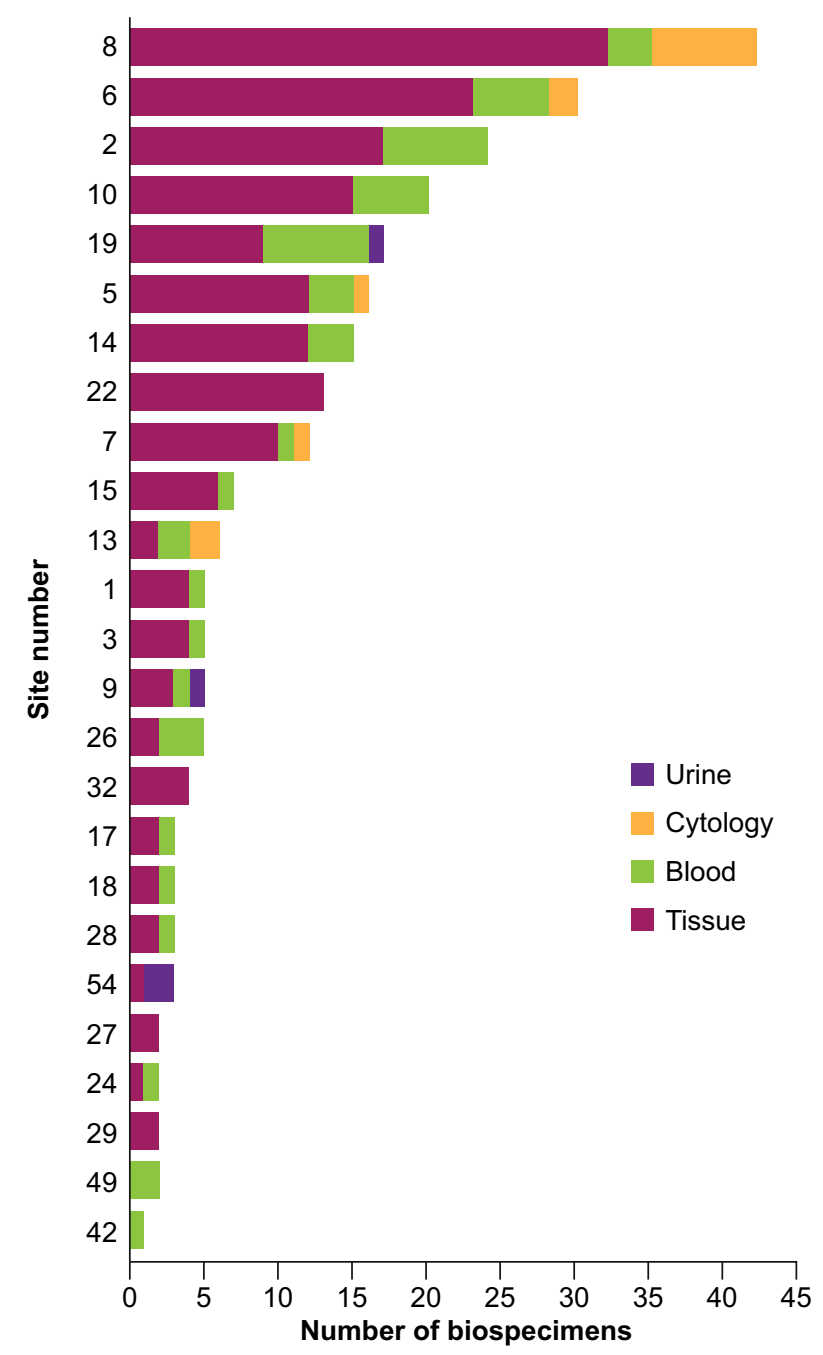

Fig. 3 Diagnostic biospecimen type by program site. $N=247$ known biospecimens; data for unknown biospecimen sample type $(n=1)$ are not shown

with gefitinib (52-62\%), erlotinib (34-63\%), or afatinib (3-26\%) [18-20]. Additional studies have also investigated the use of osimertinib in patients treated with rociletinib $[25,26]$. In one study, of the nine patients treated with rociletinib and subsequent osimertinib, three patients experienced a partial response, four had stable disease, and two had progressive disease, resulting in a $78 \%$ disease control rate [25]. In a retrospective analysis of patients treated with osimertinib following prior rociletinib treatment (US AZD9291 EAP and commercial patients), the ORR and disease control rates were 33 and $82 \%$, respectively [26]. Together, these studies demonstrate that, in the real- world setting, patients can receive clinical benefit from osimertinib following the development of EGFR-TKI resistance, also including resistance to prior third-generation EGFR-TKIs.

The overall safety profile of osimertinib in this real-world setting was consistent with that reported in controlled clinical trials [15, 18-20]. It should be noted that there were five reports of SAEs that were deemed to be treatment-related by the investigator: dyspnea, ALT increase, DVT, femur fracture, and pneumonitis. All of these five patients, however, had other comorbidities or underlying conditions that could provide possible alternative explanations for the development of these SAEs. The frequency of 
pneumonitis was also similar to that observed in previous studies in which single cases of serious or fatal pneumonitis were reported [18-20]. ILD was not observed in this patient population but has been reported in $2-4 \%$ of patients in previously published clinical trials [18-20]. The low incidence rates of dose reduction $(4 \%)$ and discontinuation $(5 \%)$ in the EAP are similar to those observed in published clinical studies [15, 18-20]. The phase 2 study (AURA2) in patients with EGFR T790M-positive NSCLC treated with osimertinib reported dose reductions and discontinuations in 3 and $5 \%$ of patients, respectively [20], with the phase 2 study extension component (AURA Extension) reporting rates of 5 and $7 \%$, respectively [18]. In the phase 3 trial (AURA3), 7\% of patients treated with osimertinib discontinued therapy [19].

Current National Comprehensive Cancer Network (NCCN) guidelines recommend testing for T790M with disease progression after firstline EGFR-TKI therapy [4]. A positive T790M mutation status can guide the decision to switch to osimertinib, which targets both EGFRsensitizing and EGFR T790M resistance mutations [16-18]. Prior to FDA approval of osimertinib, diagnostic testing upon disease progression while on EGFR-TKIs had not been routine in the USA outside of clinical trials. Now, the guidelines recommend not only EGFR T790M testing using standard biopsy samples, but also the use of the so-called "liquid biopsy" if tissue biopsy is not feasible [4]. However, if a plasma-based test is negative for the T790M mutation, re-testing via a tissue-based method should be considered $[4,27,28]$.

The type of biospecimen collected or the method used for diagnostic analysis was not restricted in this EAP. Although the majority $(92 \%)$ of EAP centers used tissue-collection methods, many EAP centers (80\%) also used minimally invasive collection methods for testing involving blood or urine, indicating early uptake of these minimally invasive methods at some centers and providing real-world evidence of their feasibility. Descriptions of the testing methods were limited to the data provided by each investigator, and information on why specific methods were used was not collected in the EAP. Other studies have demonstrated the feasibility of minimally invasive testing in both real-world and clinical trial settings [18, 19, 28-31]. With the introduction of osimertinib, an FDA-approved companion diagnostic test, the cobas ${ }^{\circledR} E G F R$ Mutation Test v2, for both tissue and plasma EGFR T790M testing was also approved [32].

Although the EAP we describe here provided real-world data regarding the safety of osimertinib and the testing methodology used for T790M analysis, there were some limitations to this program. Because most patients transitioned to the commercial supply of osimertinib after FDA approval, thus completing the EAP, the total duration of treatment with osimertinib was not captured. Furthermore, this EAP did not mandate the collection of patient response data, and, therefore, data on the efficacy of osimertinib for the entire patient population are not available. This contrasts with expanded access and compassionate-use programs conducted with other EGFR-TKIs in patients with NSCLC that have been reported in the literature [33-37]. We did not aim to provide outcomesrelated data for enrolled patients, primarily because the anticipated length of the osimertinib program would preclude any meaningful data collection. The EAP lasted approximately 6 months, which was much shorter than the expected median PFS of 10-12 months as previously reported for osimertinib [18-20]. Other published access programs were designed differently (patient population and duration) and were long enough to provide sufficient outcomes relative to the therapy of interest [33-37].

\section{CONCLUSIONS}

This assessment of the short (approx. 6-month) EAP for osimertinib with robust enrollment due to an unmet need in thoracic oncology at that time shows that osimertinib was well tolerated in previously and heavily treated patients with EGFR T790M-positive NSCLC, as demonstrated by the low rates for both dose reduction and discontinuation of osimertinib and the high rates of conversion to the commercially available agent after approval of osimertinib by the 
FDA. The results also show that testing at disease progression for T790M in patients with EGFR mutation-positive NSCLC is achievable in a real-world, non-trial setting and that there is uptake of minimally invasive collection methods for testing in this population. Testing for T790M remains an important step in patients with advanced EGFR mutation-positive NSCLC following disease progression and serves as a guide to the selection of osimertinib for appropriate patients.

\section{ACKNOWLEDGEMENTS}

We would like to thank the patients and their families, the staff at the EAP centers, and all investigators involved in this EAP for their contributions.

Funding. Funding for this program and the Article Processing Charges were provided by AstraZeneca (Wilmington, Delaware, USA). All authors had full access to all of the data in this study and take complete responsibility for the integrity of the data and accuracy of the data analysis.

Medical Writing, Editorial and Other Assistance. We would also like to acknowledge Stephanie K. Doerner, PhD, of The Lockwood Group (Stamford, Connecticut), for providing medical writing support, which was in accordance with Good Publication Practice (GPP3) guidelines and funded by AstraZeneca (Wilmington, Delaware, USA). Anja Becher, PhD, and Steven Inglis, $\mathrm{PhD}$, of Oxford PharmaGenesis (Oxford, UK), provided additional medical writing support, which was in accordance with GPP3 and funded by AstraZeneca (Wilmington, Delaware, USA).

Authorship. All named authors meet the International Committee of Medical Journal Editors (ICMJE) criteria for authorship for this article, take responsibility for the integrity of the work as a whole, and have given their approval for this version to be published.
Disclosures. Dr. Edgardo Santos declares the following: speakers bureau-Genentech, Lilly US Oncology, Boehringer Ingelheim, Celgene, Takeda, Amgen, AstraZeneca, Pfizer, Novartis, Merck. Barry Kaplan declares the following: ownership interests-Seattle Genetics shares; scientific advisory board-Celgene. Eli Kirshner declares the following-consulting/advisory relationship: AstraZeneca speakers bureau; scientific advisory board: AstraZeneca. Elisabeth F. Croft declares the following: research funding/ employment-AstraZeneca, LP and Incyte Corp. Lecia V. Sequist declares the following: consulting/advisory relationship-AstraZeneca, Pfizer, Genentech, Merck; research fundingAstraZeneca, Novartis, BI, Merrimack, Genentech. Mydoanh Chau declares the following: employee of AstraZeneca. Jiefen Munley declares the following: ownership interests. Geoffrer R. Oxnard declares the following: consulting-AstraZeneca, Inivata; honorariaSysmex, Guardant, Bio-Rad.

Compliance with Ethics Guidelines. This EAP was approved by FDA and institutional review boards, performed in accordance with the ethical principles outlined in the Declaration of Helsinki and consistent with the International Conference on Harmonisation/Good Clinical Practice Guidelines; patients provided informed consent before enrolling.

Data Availability. All data generated or analyzed during this study are included in this published article/as supplementary information files.

Open Access. This article is distributed under the terms of the Creative Commons Attribution-NonCommercial 4.0 International License (http://creativecommons.org/licenses/ by-nc/4.0/), which permits any noncommercial use, distribution, and reproduction in any medium, provided you give appropriate credit to the original author(s) and the source, provide a link to the Creative Commons license, and indicate if changes were made. 


\section{REFERENCES}

1. Brabender J, Danenberg KD, Metzger R, et al. Epidermal growth factor receptor and HER2-neu mRNA expression in non-small cell lung cancer is correlated with survival. Clin Cancer Res. 2001;7:1850-5.

2. Liu X, Wang P, Zhang C, et al. Epidermal growth factor receptor (EGFR): a rising star in the era of precision medicine of lung cancer. Oncotarget. 2017;8:50209-20.

3. Rusch V, Baselga J, Cordon-Cardo C, et al. Differential expression of the epidermal growth factor receptor and its ligands in primary non-small cell lung cancers and adjacent benign lung. Cancer Res. 1993;53:2379-85.

4. National Comprehensive Cancer Network (NCCN). NCCN clinical practice guidelines in oncology: non-small cell lung cancer version 8. https://www. nccn.org/. Accessed 8 Sep 2017.

5. Douillard JY, Ostoros G, Cobo M, et al. First-line gefitinib in Caucasian EGFR mutation-positive NSCLC patients: a phase-IV, open-label, single-arm study. Br J Cancer. 2014;110:55-62.

6. Rosell R, Carcereny E, Gervais R, et al. Erlotinib versus standard chemotherapy as first-line treatment for European patients with advanced EGFR mutation-positive non-small-cell lung cancer (EURTAC): a multicentre, open-label, randomised phase 3 trial. Lancet Oncol. 2012;13:239-46.

7. Sequist LV, Martins RG, Spigel D, et al. First-line gefitinib in patients with advanced non-small-cell lung cancer harboring somatic EGFR mutations. J Clin Oncol. 2008;26:2442-9.

8. Sequist LV, Yang JC, Yamamoto N, et al. Phase III study of afatinib or cisplatin plus pemetrexed in patients with metastatic lung adenocarcinoma with EGFR mutations. J Clin Oncol. 2013;31:3327-34.

9. Wu YL, Zhou C, Hu CP, et al. Afatinib versus cisplatin plus gemcitabine for first-line treatment of Asian patients with advanced non-small-cell lung cancer harbouring EGFR mutations (LUX-Lung 6): an open-label, randomised phase 3 trial. Lancet Oncol. 2014;15:213-22.

10. Zhou C, Wu YL, Chen G, et al. Erlotinib versus chemotherapy as first-line treatment for patients with advanced EGFR mutation-positive non-smallcell lung cancer (OPTIMAL, CTONG-0802): a multicentre, open-label, randomised, phase 3 study. Lancet Oncol. 2011;12:735-42.
11. Arcila ME, Oxnard GR, Nafa K, et al. Rebiopsy of lung cancer patients with acquired resistance to EGFR inhibitors and enhanced detection of the T790M mutation using a locked nucleic acid-based assay. Clin Cancer Res. 2011;17:1169-80.

12. Yu HA, Arcila ME, Rekhtman N, et al. Analysis of tumor specimens at the time of acquired resistance to EGFR-TKI therapy in 155 patients with EGFRmutant lung cancers. Clin Cancer Res. 2013;19:2240-7.

13. Oxnard GR, Arcila ME, Sima CS, et al. Acquired resistance to EGFR tyrosine kinase inhibitors in EGFR-mutant lung cancer: distinct natural history of patients with tumors harboring the T790M mutation. Clin Cancer Res. 2011;17:1616-22.

14. Sun JM, Ahn MJ, Choi YL, et al. Clinical implications of T790M mutation in patients with acquired resistance to EGFR tyrosine kinase inhibitors. Lung Cancer. 2013;82:294-8.

15. Janne PA, Yang JC, Kim DW, et al. AZD9291 in EGFR inhibitor-resistant non-small-cell lung cancer. N Engl J Med. 2015;372:1689-99.

16. Cross DA, Ashton SE, Ghiorghiu S, et al. AZD9291, an irreversible EGFR TKI, overcomes T790M-mediated resistance to EGFR inhibitors in lung cancer. Cancer Discov. 2014;4:1046-61.

17. Finlay MR, Anderton M, Ashton S, et al. Discovery of a potent and selective EGFR inhibitor (AZD9291) of both sensitizing and $\mathrm{T} 790 \mathrm{M}$ resistance mutations that spares the wild type form of the receptor. J Med Chem. 2014;57:8249-67.

18. Yang JC, Ahn MJ, Kim DW, et al. Osimertinib in pretreated T790M-positive advanced non-small-cell lung cancer: AURA study phase II extension component. J Clin Oncol. 2017;35:1288-96.

19. Mok TS, Wu YL, Ahn MJ, et al. Osimertinib or platinum-pemetrexed in EGFR T790M-positive lung cancer. N Engl J Med. 2017;376:629-40.

20. Goss G, Tsai CM, Shepherd FA, et al. Osimertinib for pretreated EGFR Thr790 Met-positive advanced non-small-cell lung cancer (AURA2): a multicentre, open-label, single-arm, phase 2 study. Lancet Oncol. 2016;17:1643-52.

21. Soria JC, Ohe Y, Vansteenkiste J, et al. Osimertinib in untreated EGFR-mutated advanced non-smallcell lung cancer. N Engl J Med. 2018;378:113-25.

22. Yoshioka H, Komuta K, Imamura F, et al. Efficacy and safety of erlotinib in elderly patients in the phase IV POLARSTAR surveillance study of Japanese patients with non-small-cell lung cancer. Lung Cancer. 2014;86:201-6. 
23. Zaarour M, Weerasinghe C, Nazha B, et al. Epidermal growth factor receptor tyrosine kinase inhibitors in elderly patients with non-small cell lung cancer. Expert Rev Anticancer Ther. 2015;15:1327-36.

24. Blesch KS. The normal physiological changes of aging and their impact on the response to cancer treatment. Semin Oncol Nurs. 1988;4:178-88.

25. Sequist LV, Piotrowska Z, Niederst MJ, et al. Osimertinib responses after disease progression in patients who had been receiving rociletinib. JAMA Oncol. 2016;2:541-3.

26. Gadgeel S, Chen W, Piotrowska Z, et al. P3.02b-115 Clinical activity of osimertinib in EGFR mutation positive non-small cell lung cancer (NSCLC) patients (pts) previously treated with rociletinib. J Thorac Oncol. 2017;12:S1263.

27. Oxnard GR, Thress KS, Alden RS, et al. Association between plasma genotyping and outcomes of treatment with osimertinib (AZD9291) in advanced non-small-cell lung cancer. J Clin Oncol. 2016;34:3375-82.

28. Sacher AG, Paweletz C, Dahlberg SE, et al. Prospective validation of rapid plasma genotyping for the detection of EGFR and KRAS mutations in advanced lung cancer. JAMA Oncol. 2016;2:1014-22.

29. Jenkins S, Yang J, Ramalingam S, et al. 134O_PR: plasma ctDNA analysis for detection of EGFR T790M mutation in patients (pts) with EGFR mutation-positive advanced non-small cell lung cancer (aNSCLC). J Thorac Oncol. 2016;11:S153-4.

30. Reck M, Hagiwara K, Han B, et al. ctDNA determination of EGFR mutation status in European and Japanese patients with advanced NSCLC: the ASSESS study. J Thorac Oncol. 2016;11:1682-9.
31. Thress KS, Brant R, Carr TH, et al. EGFR mutation detection in ctDNA from NSCLC patient plasma: a cross-platform comparison of leading technologies to support the clinical development of AZD9291. Lung Cancer. 2015;90:509-15.

32. Khozin S, Weinstock C, Blumenthal GM, et al. Osimertinib for the treatment of metastatic EGFR T790M mutation-positive non-small cell lung cancer. Clin Cancer Res. 2017;23:2131-5.

33. Dongiovanni D, Daniele L, Barone C, et al. Gefitinib (ZD1839): therapy in selected patients with nonsmall cell lung cancer (NSCLC)? Lung Cancer. 2008;61:73-81.

34. Heigener DF, Schumann C, Sebastian M, et al. Afatinib in non-small cell lung cancer harboring uncommon EGFR mutations pretreated with reversible EGFR inhibitors. Oncologist. 2015;20:1167-74.

35. Lee VH, Leung DK, Choy TS, et al. Efficacy and safety of afatinib in Chinese patients with EGFRmutated metastatic non-small-cell lung cancer (NSCLC) previously responsive to first-generation tyrosine-kinase inhibitors (TKI) and chemotherapy: comparison with historical cohort using erlotinib. BMC Cancer. 2016;16:147.

36. Perng RP, Yang CH, Chen YM, et al. High efficacy of erlotinib in Taiwanese NSCLC patients in an expanded access program study previously treated with chemotherapy. Lung Cancer. 2008;62:78-84.

37. Schuler M, Fischer JR, Grohe C, et al. Experience with afatinib in patients with non-small cell lung cancer progressing after clinical benefit from gefitinib and erlotinib. Oncologist. 2014;19:1100-9. 